4

\title{
Compound Flooding in Convergent Estuaries: Insights from an Analytical Model
}

3

4

5

4 Correspondence to: Ramin Familkhalili (rfamilkh@ odu.edu) 
- An idealized analytical model shows that deepening an estuarine channel reduces the impacts of river flow on peak water level but increases the effects of storm tide.

- A friction number shows the competing effects of surge time scale, depth, and convergence on water level amplitudes.

- Channel deepening changes the balance of fluvial and coastal flood risks and moves the crossover between storm tide vs. fluvial-dominated flooding landward.

\section{Abstract}

We investigate here the effects of geometric properties (channel depth and cross-sectional convergence length), storm surge characteristics, friction, and river flow on the spatial and temporal variability of compound flooding along an idealized, meso-tidal coastal-plain estuary. An analytical model is developed that includes exponentially convergent geometry, tidal forcing, constant river flow, and a representation of storm surge as a combination of two sinusoidal waves. Non-linear bed friction is treated using Chebyshev polynomials and trigonometric functions, and a multi-segment approach is used to increase accuracy. Model results show that river discharge increases the damping of surge amplitudes in an estuary, while increasing channel depth has the opposite effect. Sensitivity studies indicate that the impact of river flow on peak water level decreases as channel depth increases, while the influence of tide and surge increases in the landward portion of an estuary. Moreover, model results show less surge damping in deeper configurations and even amplification in some cases, while increased convergence length scale damps surge waves with time scales of $12 \mathrm{~h}-72 \mathrm{~h}$ along an estuary. For every modeled scenario, there is a point where river discharge effects on water level outweigh tide/surge effects. As a channel is deepened, this cross-over point moves progressively upstream. Thus, channel deepening may alter flood risk spatially along an estuary and reduce the length of a river-estuary, within which fluvial flooding is dominant.

\section{Plain language summary}

Storm surge, tides, and high river flow often combine to cause flooding in estuaries. In this study we investigate these factors and how changes to estuary and river geometry influence peak water levels. Our results show that surge waves become larger when the depth of a shipping channel is increased, for example due to dredging or sea-level rise. The same deepening, however, reduces the effect of river flow on peak water level. The result is that the region over which river influence dominates the peak water level moves upstream as a system becomes deeper. This change in the 'cross-over location' reduces the domain over which river flooding is the dominant consideration. 
understanding of how bathymetry, surge time scale, and river discharge affect surge and tidal amplitudes, and therefore flood heights and inundation, in these systems.

Keywords: Analytical model, Compound flooding, Estuary, Surge, Tide

\section{1- Introduction}

Many low-lying coastal and riverine areas have been affected by combined coastal and riverine floods over the last few decades (e.g., Jongman et al., 2012; Nicholls et al., 2007). In cases such as Hurricane Harvey (Gulf of Mexico, August 2017), flooding was driven primarily by precipitation and runoff (e.g., van Oldenborgh et al., 2017; Wang et al., 2018). Other flood events, e.g., Hurricane Sandy, were forced by the combined effects of tide and storm surge (i.e., by storm tides; Orton et al., 2016). Some storm events (such as Hurricanes Irene and Irma) produce both coastal and inland flooding because both storm surge and river flow produce elevated coastal water levels in a spatially varying pattern (e.g., Orton et al., 2012; Ralston et al., 2013; Talke et al., 2021). Collectively, a flooding event that is influenced by both storm tide and precipitation run-off is known as a 'compound flood' (e.g., Zscheischler et al., 2018; Wahl et al., 2015). The relative timing of the coastal and fluvial forcing, and the time scale over which water levels are elevated, matters in terms of impact (e.g., Zheng et al., 2014). Storm surge flooding generally occurs first and for a shorter period (i.e., time scales of hours to a day or two) than river flooding, which may last for weeks or even months, particularly in regions with a large watershed and flat topography (e.g., Johnson et al., 2016, Wong et al., 2014). The timing of storm surge relative to tidal highwater (Familkhalili and Talke, 2016) or the spring-neap tidal cycle influences flood heights, even upstream of tidal influence (Helaire et al., 2020). Therefore, understanding tidal, surge and river flow dynamics, and how they combine and interact to produce the maximum or total water level (TWL), has obvious implications for emergency planning.

The spatial variability of compound flooding is influenced by the geometry of an estuary region and may change over time due to system alterations, including channel deepening, sea-level rise, and wetland reclamation (Ralston et al., 2019; Helaire et al., 2019, 2020). Recent studies have shown that human-caused changes to the geometry of estuaries affects the dynamics of long-waves (see reviews by Talke and Jay, 2020, and Jay et al., 2021), with tidal range in some regions more than doubling (e.g., Winterwerp et al., 2013). Similar effects are observed with storm surge; for example, doubling the depth of the shipping channel in the Cape Fear Estuary was modeled to increase the magnitude of a worst-case scenario storm surge in Wilmington (NC) by $3.8 \pm 0.25 \mathrm{~m}$ to $5.6 \pm 0.6 \mathrm{~m}$ (Familkhalili and Talke, 2016). By contrast, depth increases often cause the mean water level in tidal rivers to drop, due to decreased frictional effects (Jay et al., 2011; Helaire et al., 2019); hence, flood risk in Albany (NY) has significantly dropped over the past 150 years, despite a doubling of tide range and an increase in storm surge magnitudes (Ralston et al., 2019). Closer to the coast, flood hazard within the same estuary markedly increased over the same time 
94 period (e.g., Talke et al., 2014). Hence, non-stationarity in flood hazard can be spatially variable, 95 to an extent that is just beginning to be quantified.

In this contribution, we study the relative influence of river flow and storm surge effects along the river-estuary continuum from a dynamical perspective that enables us to assess the effects of nonlinear interactions, geometry, and changing (non-stationary) conditions. An idealized approach is used, which enables a large parameter space to be assessed and the following two dynamical questions to be investigated:

a) What factors determine the region in which river flow effects or tide/surge effects dominate the total water level?

b) How does the transition from coastal to fluvial dominance shift as geometry changes or as properties of storm surge (e.g., time scale and magnitude) and river flow (magnitude) change?

We combine a three-sinusoidal wave analytical model based on Jay (1991) with the multi-wave and multi-segment approach of Giese and Jay (1989) (see Familkhalili et al., (2020) for details) to quickly query a parameter space or relevant factors and provide insight into how factors such as storm time scale and the relative magnitudes of different forcing factors influence the dynamics of compound flooding.

\section{2- Methods}

We apply an analytical approach to investigate the TWL caused by river discharge, tides, and surge in an idealized estuary. Various forms of one-dimensional analytical solutions of tidal wave propagation have long been used for idealized and real estuaries (e.g., Dronkers, 1964; Prandle and Rahman, 1980; Jay, 1991; Friedrichs and Aubrey, 1994; Savenije, 1998; Lanzoni and Seminara, 1998; Godin, 1999). More complex idealized tidal models investigate overtide generation and evolution (e.g., Chernetsky et al., 2010), the effects of variable cross-section and bottom slope (e.g., Savenije et al., 2008, Kästner et al., 2019), and the effects of multiple tidal constituents and river discharge (Giese and Jay, 1989; Buschmann et al., 2009). Other studies have used a tidal model combined with regression analysis (e.g., Godin, 1999; Kukulka and Jay, 2003a) to investigate river discharge effects. Such idealized models, by the parameter space analyzed, can be used to obtain fundamental insights into how long-waves in estuaries are affected by depth, convergence, friction, and boundary forcing.

In our approach, we develop an analytical model which is driven by three sinusoidal constituents and a constant river discharge. Our approach idealizes storm surge as the sum of two sinusoids, and neglects factors, such as the potential role of wetlands as a storage reservoir, in order to gain insight into some of the important, along-channel factors that govern the system response to a compound event. Similarly, we neglect processes such as Coriolis acceleration and gravity waves, 
and focus on the specific case of an incident, non-reflected long-wave that propagates from the coast in the landward direction and is eventually completely damped out. Moreover, we simplify our approach by considering only constant river flow conditions, a valid approximation for situations in which the time scale of a river flood event is much longer than a storm surge.

\section{2-1- Analytical model}

We use an idealized one-dimensional analytical model developed by Familkhalili et al., (2020) to investigate how combinations of tides, storm surge, and river flow affect water levels in an estuary. In this model, storm surge is approximated as the sum of a primary and a secondary sinusoidal wave. A third sinusoidal frequency is reserved for the $M_{2}$ tidal constituent. Hence, the resulting model is conceptually similar to the multi-tide constituent model developed by Giese and Jay (1989) and the three-wave model of Buschman et al., (2009), with the distinction that two of the waves are based on the amplitude and timescales of meteorologically induced storm surge rather than an astronomical tide with a known frequency.

One-dimensional long wave propagation along an idealized, funnel-shaped estuary is described by the cross-sectionally integrated equations of mass and momentum conservation (e.g., Jay, 1991; Kukulka and Jay, 2003a; Familkhalili et al., 2020):

$$
\begin{gathered}
\frac{\partial Q}{\partial t}+\frac{\partial}{\partial x}\left(\frac{Q^{2}}{A}\right)+g A \frac{\partial \xi}{\partial x}+b T=0 \\
\frac{\partial Q}{\partial x}+b \frac{\partial \xi}{\partial t}=0
\end{gathered}
$$

where $Q$ is cross-sectionally integrated flow and is the summation of the river and tidal transports $\left(Q_{R}+Q_{T}\right), t$ is time, $x$ is the longitudinal coordinate measured in landward direction (see Fig. $1 \mathrm{a}), b$ is width, $g$ is the acceleration due to gravity, $A$ is channel cross-section, $\xi$ is tidal water level elevation, $T$ is the bed stress divided by water density $\left(\frac{\tau}{\rho}=C_{d}|u| u\right), C_{d}$ is a drag coefficient, and $u=Q / A$ is the velocity. The absolute value of $u$ is assigned to preserve the directionality of stress. For simplicity, depth is assumed constant and channel width is allowed to vary exponentially with respect to the longitudinal coordinate $x$ (i.e., $b_{(x)}=B_{c}+\left(B_{0}-B_{c}\right) e^{\left(-\frac{x}{L_{e}}\right)}$, see Fig. 1a). Following Familkhalili et al (2020), we set $B_{0}=5 \mathrm{~km}$ and assume that the estuary section of the model domain is 1.5 times the convergence length which determine a constant river width of $\sim 1100 \mathrm{~m}$. The constant depth channel is routed upstream for $100 \mathrm{~km}$, to enable the tide wave to dissipate and prevent reflection off an upstream boundary. The tidal amplitude to depth ratio $\left(\frac{\xi}{h}\right)$ is assumed small, and river flow $\left(Q_{R}\right)$ is held constant (e.g., Kukulka and Jay, 2003a; Familkhalili et al., 2020). Applying these assumptions and combining Eq. (1) and (2) yields the following differential equation: 


$$
\frac{\partial^{2} Q_{T}}{\partial x^{2}}-\frac{1}{b} \frac{\partial b}{\partial x} \frac{\partial Q_{T}}{\partial x}-2 \frac{1}{g h} U_{R} \frac{\partial^{2} Q_{T}}{\partial x \partial t}+2 \frac{1}{g h} U_{R} \frac{1}{A} \frac{\partial A}{\partial x} \frac{\partial Q_{T}}{\partial t}-\frac{1}{g h} \frac{\partial^{2} Q_{T}}{\partial t^{2}}-\frac{b}{g h} \frac{\partial T}{\partial t}=0
$$

162 We linearize the frictional term $\left(T=C_{d}|u| u\right)$ using Chebyshev polynomials (Dronkers, 1964) to 163 approximate the frictional term, $u|u|$. Following Godin $(1991,1999)$, only the first and third order 164 terms of the dimensionless velocity are retained, yielding:

$$
\frac{u|u|}{U_{(x)}^{2}} \approx A u^{\prime}+B u^{\prime 3}
$$

166 where: $A=\frac{16}{15 \pi}, B=\frac{32}{15 \pi}, U_{(x)}$ is the maximum value of the total current $\left(U_{R}+U_{T}\right)$ and is a 167 function of $x$, and $u^{\prime}$ is a non-dimensionalized velocity defined as $\frac{u}{\left|U_{(x)}\right|}$ (Doodson, 1956; Godin, 168 1991). See Familkhalili et al., (2020) for additional details.

a)

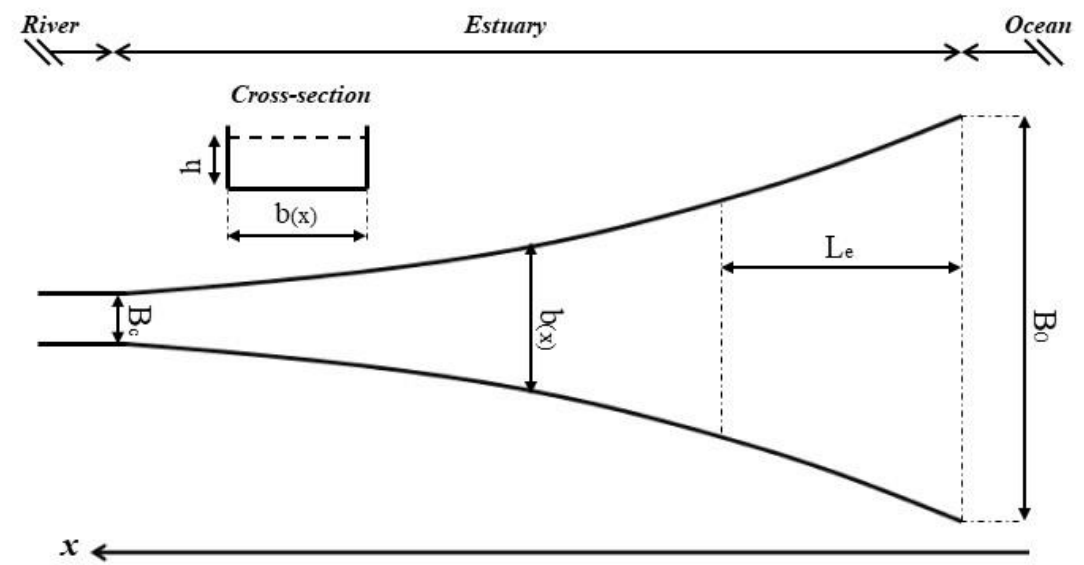

b)

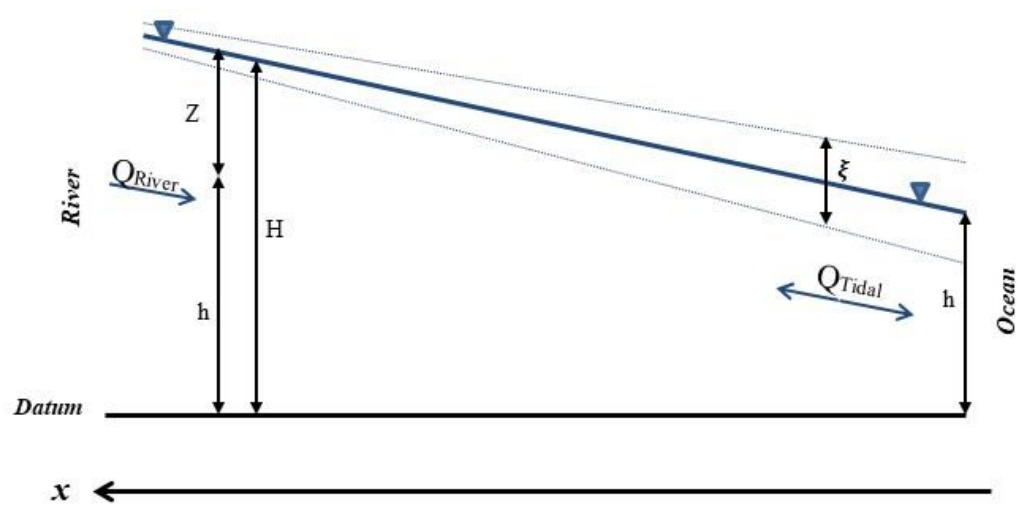


Figure 1; (a) Idealized bathymetry and plan view of the conceptual model and (b) definition of the water surface slope, modified from Kukulka and Jay (2003b). Along channel direction $x$ is upstream with $x=0$ at the ocean.

172 The sectionally and vertically averaged velocity term in Eq. (3) $(u=Q / A)$ is decomposed into three sinusoidal wave components and a constant river discharge:

$$
u=u_{r}+\sum_{i=1}^{3} u_{i} \cos \left(\omega_{i} t+\phi_{i}\right)
$$

where $u_{r}$ is the river flow velocity, and $u_{i}, \omega_{i}, \phi_{\mathrm{i}}$ are velocity amplitudes, frequencies, and phases, respectively. Although river discharge is not constant on the time scale of weather systems (5-7 day) and seasonal time scales, we assume for simplicity that the change over a tidal cycle or storm surge wave (generally $<2$ day time-scale) can be neglected. This limits our analysis to river systems with a long-response time, i.e., it is inappropriate for short, steep, flashy systems with 179 flood time scales $<2$ days.

180 We use a multi-segment approach (Dronkers, 1964), to divide the model domain into $N$ segments, 181 each has a constant depth and exponentially varying width. This approach produces a system of $2 N$ linear equations with $2(N-1)$ internal, one seaward, and one landward boundary conditions. The landward of our analytical model is forced by a no-reflection condition with constant discharge and the seaward boundary (see Fig. 1) is forced by 3 sinusoidal water level signals. One of the sine waves represents the main semidiurnal tidal constituent, and two of the sine waves represent the elevated water level of the surge signal in terms of primary and secondary components, denoted by the Pri and Sec subscripts (Familkhalili et al., 2020):

$$
\text { Surge }=\underbrace{A_{P r i} \operatorname{Cos}\left(\omega_{P r i} t+\phi_{P r i}\right)}_{\text {Surge }_{\text {Pri }}}+\underbrace{A_{S e c} \operatorname{Cos}\left(\omega_{\text {Sec }} t+\phi_{S e c}\right)}_{\text {Surge } e_{\text {Sec }}}+\underbrace{C_{1}}_{\text {Constant }}
$$

where $A$ is the amplitude, $\omega$ is the frequency, $\phi$ is the phase, and $C_{1}$ is an arbitrary offset. For simplicity, the surge is treated as a free wave within the model domain, i.e., we neglect the effect of wind stress and any locally generated component of surge.

An example fit using two sinusoidal waves to a hurricane surge is shown in Fig. 2. The surge signal is calculated by subtracting predicted tide from observed water level at Lewes, DE (NOAA Station ID: 8557380) and is caused by Hurricane Irene (August 2011). Fitting two sinusoidal waves approximates the surge signal with correlation of $R^{2}=0.95$ and root-mean-square-error of $0.05 \mathrm{~m}$ (Fig. 2). The fit is valid for the time period that the surge remains above the dashed line. 


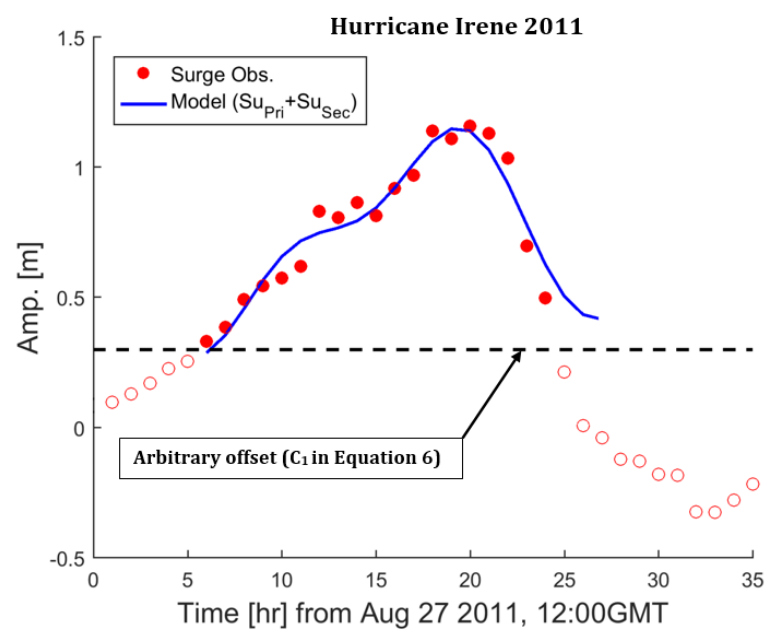

Figure 2; An example of decomposing surge into two sinusoidal waves. The red circles represent surge and are calculated by subtracting predicted tide from measured water level during Hurricane Irene (2011) at Lewes, DE (NOAA Station ID: 8557380). The blue line is the model fit that is the sum of $S u_{P r i}$ and $S u_{S e c}$ and black dashed line shows the threshold constant $C_{1}$, per Eq. (6).

Typical amplitudes, frequencies, and phases of the two component surge waves are determined by fitting two sinusoids to 354 storm surge events from Lewes, DE. These results are used to define the parameter space that we investigate (Sect. 2.4) and are typical of coastal storm surge characteristics on the mid-Atlantic Bight. Only significant events, with surges larger than $0.5 \mathrm{~m}$, are fit. The largest resulting primary surge wave amplitude was about $1.1 \mathrm{~m}$, larger than but of the same order as the main tidal constituent $\left(M_{2}=0.6 \mathrm{~m}\right)$. The statistically significant fits $\left(R^{2}=0.91\right)$ have average primary and secondary surge time scales of $\sim 29$ and $\sim 16 \mathrm{~h}$, respectively.

\section{2-2- River discharge effects on water surface slope}

The presence of river discharge $u_{R}$ and tidal velocities $u_{T}$ causes stronger ebb currents $\left(u_{R}+u_{T}\right)$ and weaker flood currents $\left(u_{R}-u_{T}\right)$. The resulting non-linear interaction and increased friction typically reduces the tidal range, shifts the timing of high and low water (e.g., Godin, 1985; Hoitink and Jay, 2016), and generates tidal distortion (asymmetry) (Parker, 1991). The increased frictional effects also influence subtidal water levels, producing a larger river slope (Kulkulka and Jay, 2003b; Buschman et al., 2009; Talke et al., 2021). However, typical coastal plain systems in the western Atlantic have low river flow relative to tidal discharge amplitudes. For example, the $\sim 200$ $\mathrm{m}^{3} / \mathrm{s}$ average annual discharge of the Saint Johns River Estuary, Florida, is about $5 \%$ of total discharge (river + tides) (Talke et al., 2021). Similarly, the Delaware River Estuary has mean and median river flows at Trenton, $\mathrm{NJ}$ of $\sim 340 \mathrm{~m}^{3} \mathrm{~s}^{-1}$ and $285 \mathrm{~m}^{3} \mathrm{~s}^{-1}$, respectively, small compared to tidal flow of $\sim 23 \times 10^{4} \mathrm{~m}^{3} \mathrm{~s}^{-1}$ at the mouth (USGS, 2018; Munchow et al., 1992). The Cape Fear 
220 River has an average river discharge of $268 \mathrm{~m}^{3} \mathrm{~s}^{-1}$ (Familkhalili and Talke, 2016), which is less than $5 \%$ of total averaged ebb-tidal flow (Olsen, 2012).

River flow alters the water surface slope, and this behavior influences the spatial distribution of total water level (e.g., Fig. 1b). Here, we use the tidally averaged one-dimensional equation of motion to investigate water level gradients, following Kukulka and Jay (2003b) and Godin (1999). For simplicity, no component of mean water level caused by the tidal Stokes drift is considered. The parameter $h$ is the mean depth of water, $\xi$ is the tidal amplitude (small compared to depth), $Z$ is the perturbation in the water surface elevation due to river discharge $Q$, and is assumed to be much smaller than $h$. In this study, river flow velocity (applied at the upstream boundary) is parameterized as the ratio of the river velocity magnitude to the magnitude of the major tidal component velocity at the ocean boundary (i.e., $\frac{\left|u_{r}\right|}{\left|u_{D_{2}}\right|}$ or $\theta$ hereafter). To evaluate the effect of elevated river discharge, we consider a river flow ratio of 0 to 1 . The ratio of $\theta=1$ represents a case in which river and tidal flows are comparable, and thus is outside the zone of our assumptions; however, comparisons with numerical model results suggest that results below this ratio are reasonable (see Sect. 2.3). Therefore, we assess both low-flow conditions and conditions in which the river flow is comparable to tidal discharge.

Previous studies (e.g., Ralston et al., 2019; Helaire et al., 2019; Talke et al., 2021) showed that reduced friction due to increased channel depth can alter the tidally averaged water level gradient

$\left(\frac{\partial Z}{\partial x}\right.$, Fig. 1b). River slope can be determined from the one-dimensional equation of motion (Godin, 239 1999):

$$
\underbrace{\frac{1}{g} \frac{\partial \bar{u}}{\partial t}}_{\begin{array}{c}
\text { Local } \\
\text { acceleration }
\end{array}}+\underbrace{\overline{\bar{u}} \frac{\partial \bar{u}}{\partial x}}_{\begin{array}{c}
\text { convective } \\
\text { acceleration }
\end{array}}=-\underbrace{\frac{\partial H}{\partial x}}_{\begin{array}{c}
\text { Pressure } \\
\text { gradient }
\end{array}}-\frac{\bar{u}|\bar{u}|}{\underbrace{C_{h}^{2}(h+\xi)}_{\text {Friction }}}
$$

240 where $\bar{u}$ is tidally averaged value of the current at $x, g$ is the acceleration due to gravity, $C_{h}$ is 241 Chézy coefficient, and $h$ is the mean depth of water. Scaling the terms in Eq. (7) using values 242 typically found in estuaries (e.g., Godin and Martinez, 1994; Kukulka and Jay, 2003b, Buschman 243 et al., 2009) shows that zero-order balance is between the pressure gradient and the friction term, 244 so that the entire left-hand side of Eq. (7) can be neglected as small, though the convective term 245 may be locally important in real systems with complex geometry (e.g., Helaire et al., 2019).

246 Since the cross-sectional area in our model varies smoothly (exponentially) over a large length 247 scale, our approach neglects convective effects. We neglect the riverbed slope, since the bed slope 248 in estuaries is typically small (order $10^{-5}$ ), particularly in modern dredged systems (see e.g., Talke 249 et al., 2021). Within the upstream reaches of tidal rivers, the bed slope often increases and is 250 important dynamically (Kästner et al., 2019); therefore, we restrict our analysis and interpretation 
251 to estuarine reaches. As before, we assume that the tidal amplitude to depth ratio $\left(\frac{\xi}{h}\right)$ is small. Given 252 these assumptions, we simplify Eq. (7) to the following balance (Godin and Martinez, 1994):

$$
\frac{\partial \bar{H}}{\partial x}=-\frac{\bar{u}|\bar{u}|}{C_{h}^{2} \bar{h}}
$$

where $\bar{H}$ is elevation and $\bar{h}$ is the mean water level (the overbar denotes the tidally averaged value). The low-frequency momentum Eq. (8) shows that the surface slope is defined by the bed stress term. Considering the first and third terms in Eq. (4), we use a quasi-linear form of the quadradic velocity term (i.e., $\bar{u}|\bar{u}|$ ) to solve the equation (see Sect. 2.1).

\section{2-3- Model validation}

The tide-surge analytical model was previously compared against the tidal amplitude variation of two one-constituent analytical models (the Toffolon and Savenije, 2011 and Jay, 1991 tidal solutions) and idealized Delft-3D numerical model results (see Familkhalili et al., 2020). Results showed that our analytical model is capable of capturing wave amplitudes that are in good agreement with numerical models results. Here we update the validation to include the effects of river flow and compare our results against idealized Delft-3D numerical model results that are run under the same bathymetry and forcing. Analytical/numerical comparisons were made for a weakly convergent and strongly dissipative estuary with constant depth of $5 \mathrm{~m}$ and a width profile defined by $B_{0}=5 \mathrm{~km}, L_{e}=80 \mathrm{~km}$, and $B_{c}=400 \mathrm{~m}$ (see Fig. 1). Both analytical and numerical models are forced by the $K_{1}, M_{2}$, and $M_{3}$ tidal constituents with amplitudes of $0.25,0.5$, and 0.25 $\mathrm{m}$, respectively at the ocean boundary, two of which $\left(K_{1}\right.$ and $\left.M_{3}\right)$ combined represent a surge wave. We further analyze the numerical model results by using harmonic analysis (e.g., Leffler and Jay, 2009).

Figure 3 shows the spatial pattern of the dominant tidal constituent $\left(M_{2}\right)$ amplitude normalized by its value at the estuary mouth. The analytical model results closely resemble the numerical model results with a root-mean-square error of $0.02 \mathrm{~m}$ for both the three-wave model with and without river flow (blue and red colors in Fig. 3), showing that this idealized analytical model can properly estimate spatial variability of surge along an estuary.

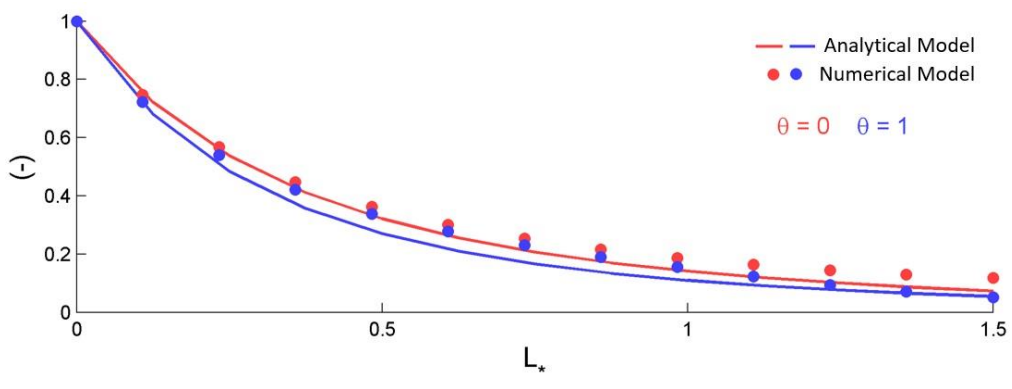


Figure 3; Dominant tidal constituent $\left(M_{2}\right)$ amplitude in a $5 \mathrm{~m}$ deep estuary for three tides models $\left(K_{1}, M_{2}\right.$, and $\left.M_{3}\right)$ with and without river flow $(\theta=0-1)$. The $x$ axis is the estuary length normalized by the convergence length scale ( $L_{*}=x / L_{e}$ ) and the vertical axis is normalized by $M_{2}$ amplitude at the ocean boundary $\left(L_{*}=0\right)$.

In addition, results for tidally averaged water levels (i.e., Z; see Fig. 1) under conditions of tidal and river-flow forcing are consistent with numerical models. The water level profiles vary with $\theta$ (flow) for both the analytical model (dashed lines) and the numerical model (solid lines) as shown in Fig. 4 for a weakly convergent estuary. In general, the analytical model slightly underestimates numerical results. The RMSE between the numerical and analytical surface profiles are $0.03,0.08$, $0.09,0.10 \mathrm{~m}$ for a $\theta$ of $0,0.25,0.5$, and 1.0 , respectively, or roughly $3-8 \%$ of the total superelevation above sea-level (Fig. 4a).

a)

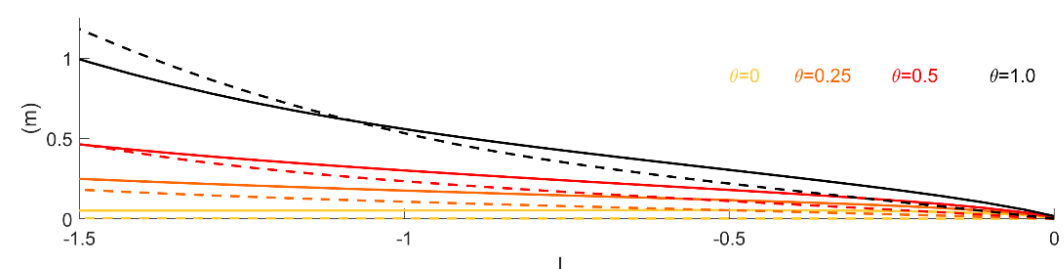

b)

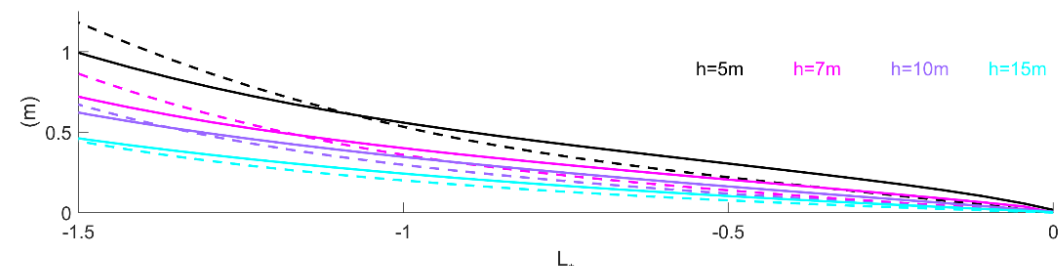

Figure 4: (a) The importance of river flow (i.e., $\theta$ at $L_{*}=1.5$ ) for $5 \mathrm{~m}$ depth and (b) the importance of channel depth for $\theta=1$ in an idealized three sinusoidal waves model. Vertical axis is tidally averaged water level and horizontal axis represents dimensionless coordinate system of $L_{*}=x / L_{e}$. Solid and dashed lines represent numerical and analytical model results, respectively. The black solid and dashed lines represent same scenario $(h=5 \mathrm{~m}, \theta=1)$ in both (a) and (b).

Larger river discharge (greater $\theta$ ) produces higher mean water levels $(Z$ ), as expected (see Fig. 4a). As river discharge increases (Fig. 4a), the depth averaged velocity increases, and a larger water surface slope $\left(\frac{\partial \bar{H}}{\partial x}\right)$ is needed to balance the Eq. (8). Equation (8) also shows that a shallower estuary (smaller $h$ ) has a similar impact on water surface slope as increasing averaged river flow velocity (larger $u$ ) (see also Talke et al., 2021). Shallower depth $(h)$ causes a steeper surface slope (Eq. (8)), because a larger pressure gradient is required to drive the flow downstream (see also Hoitink and Jay, 2016). Similarly, increased depth reduces frictional effects and result in lower mean water levels (Fig. 4b). For example, increasing depth from $h=5 \mathrm{~m}$ (black dash line in Fig. $4 \mathrm{~b}$ ) to $h=10 \mathrm{~m}$ results in an up to $0.55 \mathrm{~m}$ reduction in mean water level (at $L_{*}=1.5$ ). The effects of deeper shipping 
302 channel on mean water levels are also observed and modeled in the Hudson and Columbia River

303 estuaries (Ralston et al., 2019; Helaire et al., 2019).

304 Each incremental increase in depth produces a smaller change in the slope ( $\left.d Z / d L_{*}\right)$; for example, the change in the water level profile between $5 \mathrm{~m}$ and $10 \mathrm{~m}$ is larger than a similar proportional 306 change from $10 \mathrm{~m}$ to $15 \mathrm{~m}$ (Fig. 4b). Consistent with other studies (e.g., Kukulka and Jay, 2003b; 307 Hoitink and Jay, 2016), both the analytically and numerically modeled water level slope ( $\left.d Z / d L_{*}\right)$ 308 is largest upstream and becomes significantly less near the coast. This is driven by the decreased 309 river velocity (and friction) due to the increase in cross-sectional area in the estuary. Therefore, 310 we expect that varying the forcing conditions will most impact mean water levels more upstream, 311 due to greater total river velocity magnitudes in the landward part of the system.

\section{2-4- Dimensional and non-dimensional parameter space studied}

313 We use our validated analytical model to further investigate the effects of channel depth, river 314 flow, channel width convergence, and surge time-scale on the spatial evolution of water levels 315 along estuaries. For all simulations, the primary tidal constituent period and amplitude are fixed to $31612 \mathrm{~h}$ (i.e., a semidiurnal or $D_{2}$ wave) and $0.5 \mathrm{~m}$, respectively, a value that is typical of the semi317 diurnal tide wave on the U.S. East Coast (Table 1). To study the effects of width convergence, we 318 test both weakly $\left(L_{e}=80 \mathrm{~km}\right)$ and strongly convergent $\left(L_{e}=20 \mathrm{~km}\right)$ conditions (see e.g., Jay, 1991; 319 Lanzoni and Seminara, 1998). Table 1 shows the parameter space used in the model. The primary 320 and secondary surge amplitudes are set to be 0.5 and $0.25 \mathrm{~m}$, respectively (Eq. (6)) and the estuary 321 mouth $\left(B_{0}\right)$ is assumed to have a width of $5 \mathrm{~km}$. Sensitivity analysis is done by varying the parameters in Table 1 individually, with other parameters held constant, resulting in a total of 128 parameter combinations (i.e., four different values for depths, four different values for river flow, four different time scales combination, and two convergence length scales).

Table 1: Parameter space used in analytical model

\begin{tabular}{|c|c|}
\hline Channel Depth $(m)$ & $5,7,10,15$ \\
\hline Su $u_{\text {Pri }}$ Amp. $(m)$ & 0.5 \\
\hline Su $u_{\text {Sec }}$ Amp. $(m)$ & 0.25 \\
\hline$\left(\begin{array}{c}\text { Su } \text { Pri }_{\text {Time Scale }(h)} \text { Time Scale }(h)\end{array}\right)$ & $\left(\begin{array}{c}12 \\
6\end{array}\right),\left(\begin{array}{c}24 \\
12\end{array}\right),\left(\begin{array}{l}48 \\
24\end{array}\right),\left(\begin{array}{l}72 \\
36\end{array}\right)$ \\
\hline$D_{\text {Sec }}$ Amp. $(m)$ & 0.5 \\
\hline$D_{2}$ Time Scale $(h)$ & 12 \\
\hline
\end{tabular}




\begin{tabular}{|c|c|}
\hline Upriver flow velocity $\left(\theta=\frac{\left|u_{r}\right|}{\left|u_{D_{2}}\right|}\right)$ at $L_{*}=1.5$ & $0,0.25,0.5,1$ \\
\hline$L_{e}$ Convergence length scale $(\mathrm{km})$ & 80 (weakly convergent), 20(strongly convergent) \\
\hline
\end{tabular}

326

Non-dimensional variables provide insights into which parameters produce the most effect on system response. From the scaling of Eq. (3) (see also Familkhalili et al., 2020), we derive the three most relevant independent non-dimensional variables:

- Parameter $(\Omega)$ represents the ratio of $S u_{P r i}$ time scale to $D_{2}$ period and represents the influence of primary surge wave time scale on tide-surge interactions.

- The friction number $\left(\psi=\frac{C_{d} \xi \omega^{2} L_{e}^{3}}{g h^{3}}\right)$ shows the effects of changing surge wave properties, which are influenced by depth $(h)$, surge frequency $\left(\omega=\frac{1}{T}\right)$, and convergence length-scale $\left(L_{e}\right)$; all affect the damping or amplification of surge waves.

- Parameter $(\theta)$ represents the ratio of upriver velocity (at $\left.L_{*}=1.5\right)$ to the major tidal component $\left(D_{2}\right)$ velocity at the estuary mouth.

For plotting purposes, we define two additional non-dimensional numbers: $S u_{\text {Pri }}$ normalized amplitude $\left(A_{*}=\frac{A m p . S u_{P r i}}{\text { Surge Amp. at Boundary }}\right)$ and a dimensionless coordinate system of $L_{*}=x / L_{e}$, where $L_{*}$ is normalized length.

In our models we assume that the two surge waves are symmetric with a phase lag ( $\phi$ in Eq. (5)) of zero degrees between $S u_{P r i}$ and $S u_{S e c}$, resulting in a repeating and symmetric storm surge wave (see Fig. 5). This simulates a storm surge in which there is initially a draw-down in water level, followed by the positive storm surge. To test the most frictional case, we also define the relative phase lag between the $D_{2}$ wave and surge to be zero.

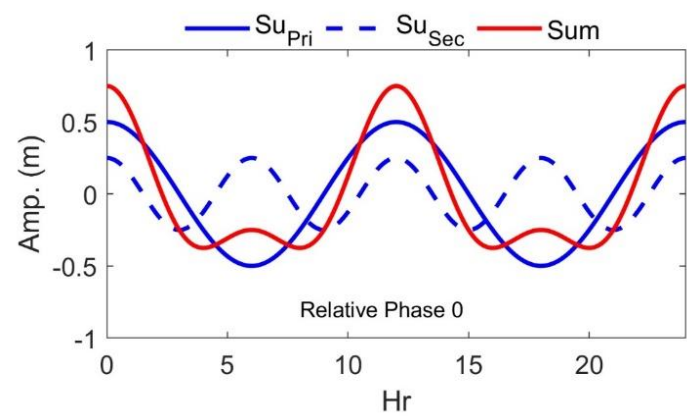


Figure 5; A symmetric surge wave which is the result of two sinusoidal waves (i.e., $S u r g e=S u_{P r i}+S u_{S e c}$ ).

\section{3- Results and discussion}

We employ the validated model to study how bathymetry, river discharge, and surge characteristics affect water floods in an idealized estuary. First, the effects of surge amplitude and time scale on water levels are examined. Then, the effects of river discharge and width convergence on surge amplitude are presented, and finally compound flooding of tide, surge, and river flow is investigated.

\section{3-1- Effects of wave characteristics on water level}

The influence of wave characteristics (i.e., time scale and magnitude) on tidally averaged water level is tested by modeling a set of waves with time scales of $12 \mathrm{~h}$ and $24 \mathrm{~h}$ and amplitudes of 0.5 $\mathrm{m}$ and $1 \mathrm{~m}$ at the ocean boundary. Model results confirm, as suggested by the friction number $(\psi)$, that increasing wave time scale $\left(T=\frac{1}{\omega}\right)$ or decreasing wave amplitude $(\zeta)$ has similar effect as increasing depth $(h)$ and therefore would result in lower mean water levels (see Fig. 6). Figure 6 shows that increasing wave time scale from $12 \mathrm{~h}$ (red lines) to $24 \mathrm{~h}$ (blue lines) would reduce the mean water level at $L_{*}=1.5$ from $0.75 \mathrm{~m}$ to $0.5 \mathrm{~m}$, and from $1.56 \mathrm{~m}$ to $1.10 \mathrm{~m}$ for wave amplitudes of $0.5 \mathrm{~m}$ and $1 \mathrm{~m}$ at the ocean boundary $\left(L_{*}=0\right)$, respectively. In other words, for the same boundary amplitude, a shorter time scale wave produces larger mean water levels landward.

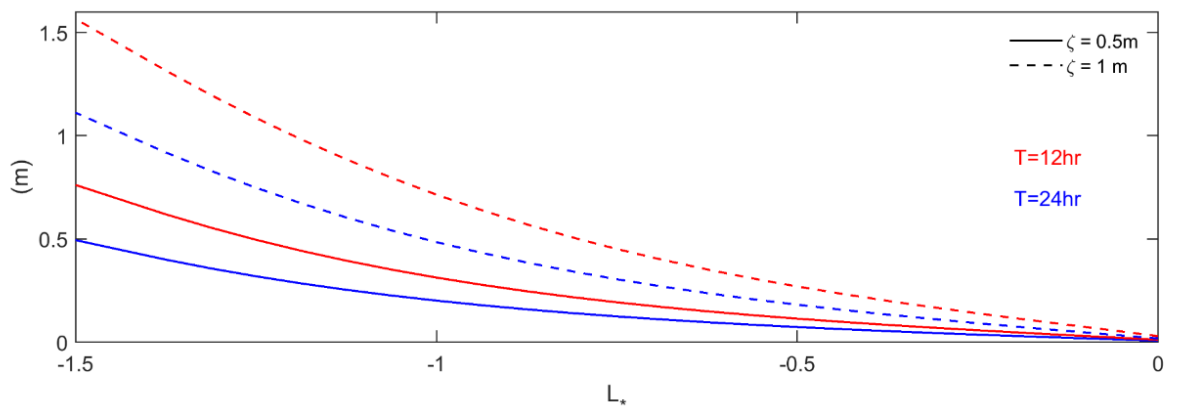

Figure 6: The effects of wave time scale (i.e., $12 \mathrm{~h}$ and $24 \mathrm{~h})$ and amplitude $\left(0.5 \mathrm{~m}\right.$ and $1 \mathrm{~m}$ at the ocean boundary $L_{*}=$ 0 ) on tidally averaged water level for $5 \mathrm{~m}$ depth channel in an idealized one sinusoidal wave model for $\theta=1$. Vertical axis is tidally averaged water level, and the horizontal axis represents the estuary length normalized by the convergence length scale (i.e., $L_{*}=x / L_{e}$ ).

\section{3-2- Frictional effects of river discharge on surge amplitude}

370 The rate at which a surge decays away from the ocean entrance varies with river flow and surge 
372 length-scale of $S u_{P r i}$ normalized amplitude $\left(A_{*}=\frac{A m p \text {. }}{A m p \text {. at ocean boundary }}\right)(e$-folding is defined as 373 the lengthscale required to get to $1 / \mathrm{e} \sim 38 \%$ of boundary values). The longer the wave period, the 374 more slowly surge amplitude $A_{*}$ decreases as the surge moves landward (keeping all other 375 variables constant). For example, Fig. 7a shows that a $12 \mathrm{~h}(\Omega=1)$ surge amplitude reaches an $e$ 376 folding reduction in amplitude at $\sim 0.4 L_{*}$ compared to $\sim 0.9 L_{*}$ for the $72 \mathrm{~h}(\Omega=6)$ surge. The lower 377 rate of spatial decay of surge amplitude for lower frequency surge waves is caused by their lower 378 velocity and consequent smaller frictional effects.

379 Model results also show that higher river discharge will increase the damping of surge amplitudes 380 (Fig. 7). When $(\theta=0)$, river flow is zero and only tide-surge nonlinear interactions can occur. 381 Hence, surge amplitudes decay more slowly for $\theta=0$ than for $\theta>0$ (compare the $\theta=0$ and $\theta=$ 3821 cases in Fig. 7). The slanted contour lines highlight the effects of river flow; as $\theta$ increases, the $383 e$-folding length-scale of normalized amplitude $\left(A_{*}\right)$ reduces for all surge time scales $(\Omega=1-6)($ Fig. $3847 \mathrm{a}-\mathrm{d})$. Adding river flow to a surge with a primary time-scale of $12 \mathrm{~h}(\Omega=1)$ reduces the $e$-folding 385 scale of damping from $0.4 L_{*}(\theta=0)$ to $0.34 L_{*}(\theta=1)$, for the $5 \mathrm{~m}$ depth case $(\sim 15 \%$ decrease; 386 Fig. 7a). The percent decrease in the $e$-folding scale is larger in a deeper, $15 \mathrm{~m}$ channel, and 387 decreases from $1.15 L_{*}$ to $0.95 L_{*}$ ( $18 \%$ decrease; Fig. $\left.7 \mathrm{~d}\right)$.

388 Surge amplitudes also decay more slowly (larger $e$-folding) in a deeper channel for all surge time 389 scales (Fig. 7). Sensitivity studies show that the largest difference in normalized amplitude 390 between a $12 \mathrm{~h}(\Omega=1)$ and $72 \mathrm{~h}(\Omega=6)$ surge occurs at larger depth $(h=15 \mathrm{~m})$ with changes of $391 \sim 1 L_{*}$ to $3.5 L_{*}$ in the $e$-folding length-scale of damping (Fig. $7 \mathrm{~d}$ ). Increasing the river discharge 392 relative to the $M_{2}$ velocity (larger $\theta$ ) reduces the amplification of the surge wave and therefore the $393 e$-folding length scale of $A_{*}$ reduces from $\sim 3.5 L_{*}$ to $\sim 2.4 L_{*}$ for $S u_{P r i}$ of $72 \mathrm{~h}$ (Fig. $7 \mathrm{~d}$ ). 

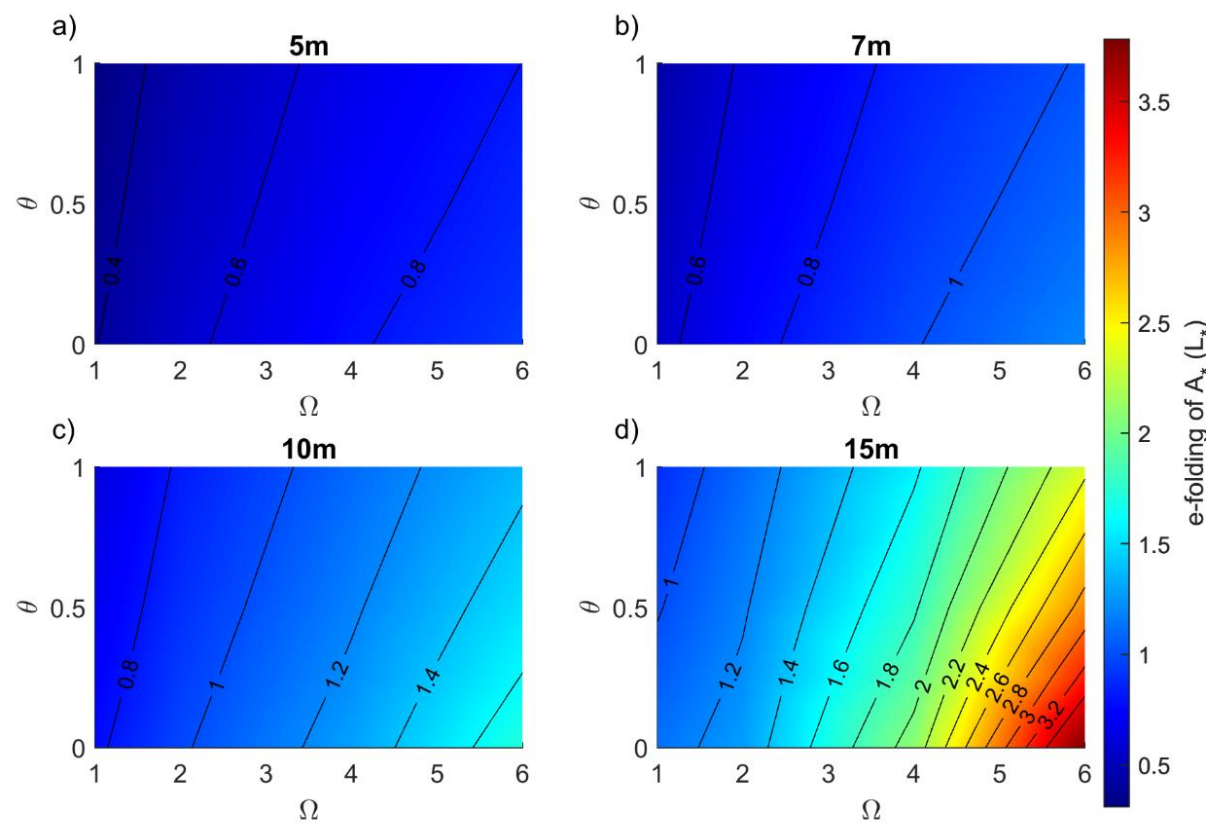

395 Figure 7: The effects of river flow $\left(\theta=\frac{\left|u_{r}\right|}{\left|u_{D_{2}}\right|}\right)$ and surge periods $\left(\Omega=\frac{\text { Period } S u_{P r i}}{\text { Period } D_{2}}\right)$ along an idealized weakly 396 convergent estuary for channel depth of (a) $5 \mathrm{~m}$, (b) $7 \mathrm{~m}$, (c) $10 \mathrm{~m}$, and (d) $15 \mathrm{~m}$. The color scaling represents the $e$ folding length-scale of primary surge normalized amplitude $\left(A_{*}\right)$.

\section{3-3- Effects of width convergence on surge amplitude}

Long-wave propagation along an estuary is characterized by a balance of inertial effects, friction, and convergence. Figure 8 shows the normalized amplitude $\left(A_{*}\right)$ of the primary surge wave for weakly convergent (left panel, 8a and 8c) and strongly convergent estuaries (right panel, $8 \mathrm{~b}$ and $8 \mathrm{~d})$, for a $12 \mathrm{~h}$ surge time scale $(\Omega=1)$. The contours represent the $e$-folding length scale of primary surge normalized amplitude and the $x$-axis represents the dimensionless coordinate system of $L_{*}=$ $x / L_{e}$. The factor $4 \mathrm{X}$ change in convergence length scale from $80 \mathrm{~km}$ (Fig. 8a, 8c) to $20 \mathrm{~km}$ (Fig. $8 \mathrm{~b}, 8 \mathrm{~d})$ alters the friction scale $(\psi)$ by a factor of 64 .

The convergence of an estuary influences surge amplitudes (Fig. 8), similar to its well-known effects on tidal amplitudes (e.g., Jay, 1991). All surge amplitudes decrease landward for all depth cases in a weakly convergent $\left(L_{e}=80 \mathrm{~km}\right)$ estuary; effectively, convergence effects are much smaller than the bed friction and gravity effects and therefore long-wave amplitudes decrease (Fig.

$4108 \mathrm{a}$ and 8c). Under strongly convergent conditions with no river flow, the primary surge amplitude 411 decays less quickly in a deeper channel as it moves upstream than under weakly convergent 412 condition (see Fig. 8a, b), and can even increase in the inland direction (see Fig. 8b). By contrast, 413 increased river discharge produces greater damping in the surge wave (compare Fig. 8a and 8c, or 
414 Fig. 8b and 8d). For example, for friction factor of $\psi=0.5(h=6.5 \mathrm{~m})$ and a location of $L_{*}=1$, 415 the surge wave has damped to $60 \%$ of its boundary value when the tidal to river flow ratio is $\theta=1$ 416 (Fig. 8d) but is at $70 \%$ of its boundary value when there is no river discharge (Fig. 8b). Hence, 417 increasing river flow and decreasing channel depth both cause larger damping in the surge wave.
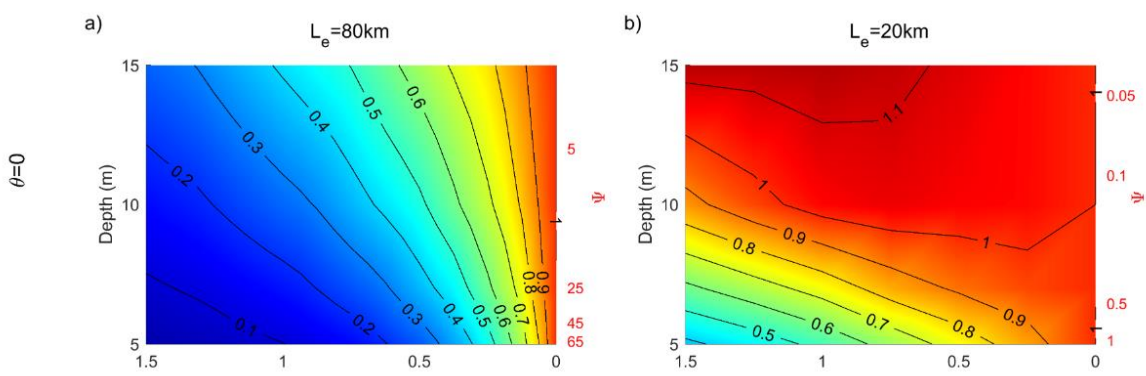

c)

d)

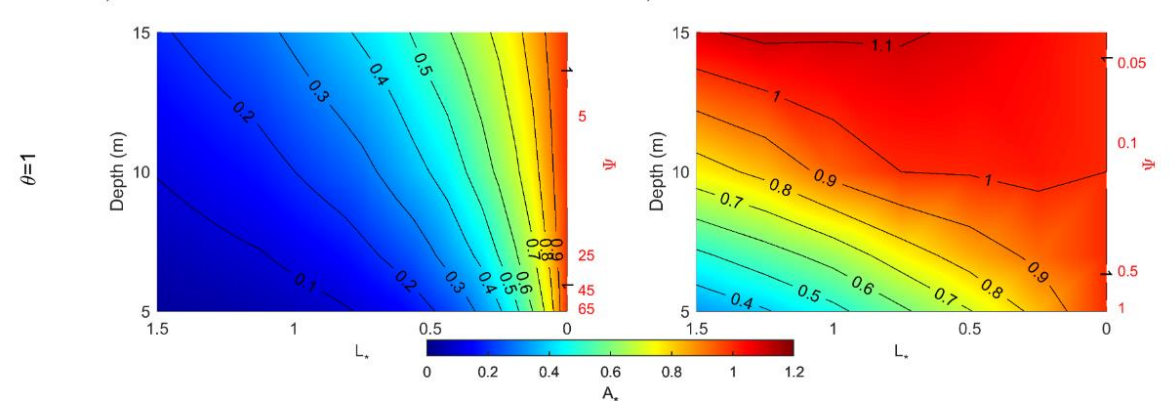

Figure 8: The effects of convergence length scale and river discharge on primary surge $(12 \mathrm{~h}, \Omega=1)$ amplitude $\left(A_{*}\right.$ is normalized amplitude) along a weakly convergent estuary, $L_{e}=80 \mathrm{~km}$ (subplots a, c) and strongly convergent estuary, $L_{e}=20 \mathrm{~km}$ (subplots b, d). Left hand side vertical axis is channel depth and right-hand side vertical axis is the corresponding non-dimensional friction number $\left(\psi=\frac{C_{d} \xi \omega^{2} L_{e}^{3}}{g h^{3}}\right)$ and horizontal axis represents dimensionless coordinate system of $L_{*}=x / L_{e}$.

\section{3-4- Combined effects of tide, surge, and river flow on total water levels}

We next investigate how variations in river flow influence the Total Water Level (TWL), which is the summation of tide, storm surge, and river discharge effects ( $\mathrm{TWL}=\mathrm{T}+\mathrm{SS}+\mathrm{R})$. The highest possible total water level (HTWL) during such a compound event occurs when the tide $\left(D_{2}\right)$ and surge have zero relative phase (i.e., the surge occurs at high water) and when the peak river flow occurs at the same time. Because the timing of a meteorological event is usually random relative to tides, and because peak surge usually precedes peak river discharge, HTWL rarely if ever occurs. However, it is a useful metric of the potential flooding. Such a worst-case scenario could occur, for example, when multiple storms occur in close succession. The HTWL therefore provides a way to compare different parameter regimes and evaluate the effect of long-term changes in the geometry of an individual estuary. 
a)
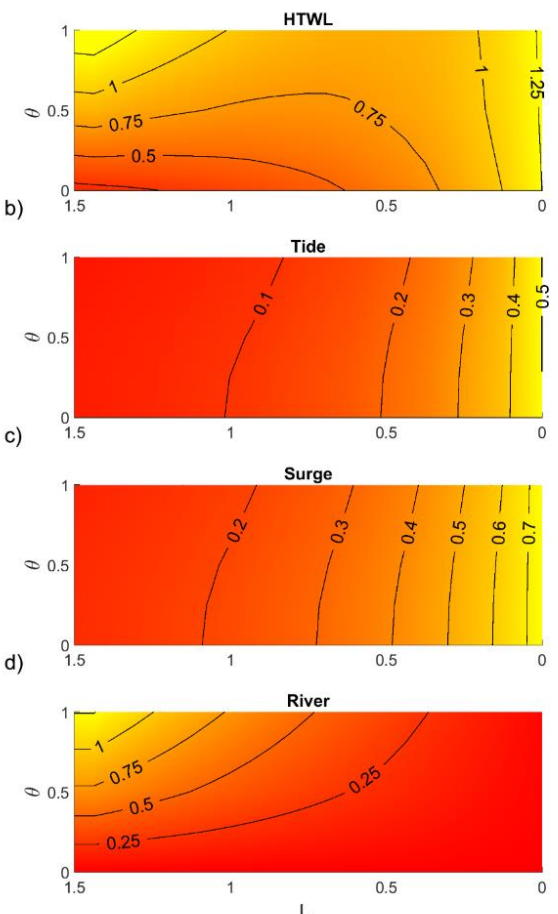
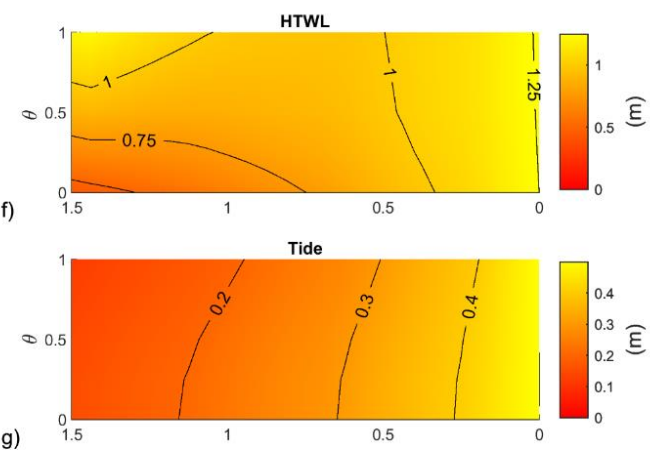

g)
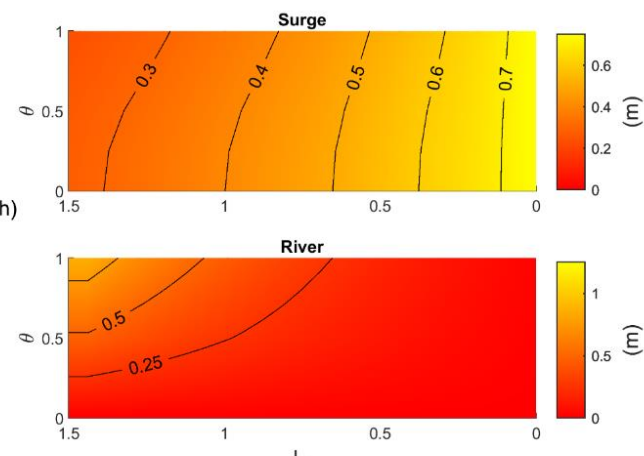

435

Figure 9: Combined contribution of tide, surge, and river flow to water level for depths of $5 \mathrm{~m}$ (left panel subplots) and $10 \mathrm{~m}$ (right panel subplots). Colors and the labeled contours denote water level. The total water level (a and e) is the combination of tidal amplitude ( $b$ and $\mathrm{f}$ ), surge amplitude ( $\mathrm{c}$ and $\mathrm{g}$ ) and water level from river discharge ( $\mathrm{d}$ and h). The period of the primary surge $\left(S u_{P r i}\right)$ is $24 \mathrm{~h}$, the convergence length scale is $80 \mathrm{~km}$, the $x$-axis represents dimensionless coordinate system of $L_{*}=x / L_{e}$ (origin at estuary mouth, on right-hand side) and the $y$-axis shows the non-dimensional river flow $\left(\theta=\frac{\left|u_{r}\right|}{\left|u_{D_{2}}\right|}\right)$. Note the difference in color-bar scales between plots.

The HTWL (Fig. 9a and 9e) follows a pattern set by the contradictory effects of river flow and marine forcing (tides and surge). Far upstream $\left(L_{*}=1.5\right)$, river water levels are the largest factor, particularly for larger $\theta$, and decay in the downstream direction (Fig. $9 \mathrm{~d}$ and $9 \mathrm{~h}$ ). The surge and tidal components of water level (e.g., Fig. 9b, 9c) decay in the opposite direction, from the oceanic boundary towards the upstream boundary. For larger river flows $(\sim \theta>0.5)$ and this parameter space, the counteracting factors produce a minimum HTWL in the middle part of the domain $\left(L_{*}=\right.$ 0.5-1.0). For small river flows, water levels monotonically decrease in the upstream direction.

Importantly, the HTWL is not merely the superposition of river flow, tide, and surge effects, considered in isolation. Rather, as shown by the non-vertical contour lines for tides and surge (e.g., Fig. 9f and 9g), increases in the relative influence of river flow (larger $\theta$ ) tend to reduce the magnitude of tides and surge (see also Helaire et al., 2020). By contrast, increases in long-wave 
453 magnitudes (tides, surge) at the ocean boundary increase the tidally averaged water level profile, 454 as already established (Fig. 6; see also Buschman et al., 2009 and Talke et al., 2021). 455 Simultaneously, long-wave magnitudes decrease more quickly, the larger they are at the estuary 456 boundary (see also Familkhalili et al., 2020). Effectively, each component of water level influences 457 the other, and itself: for example, tides within the domain depend on self-interaction (e.g., the 458 boundary magnitude matters), and also on tide-surge and tide-river interaction. While the overall 459 influence in terms of magnitude is relatively minor for the parameter space in Fig. 9, these 460 observations show that non-linear tide-surge-river interactions during a compound event cannot 461 be neglected.

462 Changes in the depth of an estuary, whether by dredging, sea-level rise, or morphodynamic change, 463 also exert a strong, spatially variable influence on the HTWL (Fig. 9 and 10). When depth is small $464\left(5 \mathrm{~m}\right.$; Fig. 9a), the HTWL is greater in the upstream domain $\left(L_{*}=1.5\right.$ and $\left.\theta>0.5\right)$ than in a larger 465 depth case (10m; Fig. 9e). This occurs because a larger average river slope is needed to push the 466 same amount of water seaward when depth is small, as suggested by Eq. (8) (see also Talke et al., 467 2021). However, smaller depths also lead to greater dissipation and frictional effects in the tide 468 and surge wave, due to the same reduction in hydraulic drag (compare right-hand and left-hand 469 side of Fig. 9, and their difference (Fig. 10)). Hence, tide and surge amplitudes increase when 470 depth is increased, for all river discharges $(\theta=0-1$; Fig. 10b, c). The percent increase is less for 471 higher river discharge; this is shown by the contours that slant rightwards (Fig. 10b and 10c). 472 Further, both tides and surge show a region of maximum change, located in mid-estuary (between $473 L_{*} 0.5$ to 1 ; Fig. 10). Near the ocean boundary, changes are relatively small, also in percentage 474 terms. Far upstream, the percent change in tidal range may still be significant, but the magnitudes 475 themselves are small (see also Talke et al., 2021).

476 The differences in the response of river flow and storm surge to a depth increase lead to a crossover 477 point, which we define as the location in which river flow effects are larger than marine effects, 478 for a given set of forcing conditions (see the zero-contour line in Fig. 10a). Since the crossover 479 point moves upstream as depth increases (Fig. 11), processes such as dredging, erosion, or sea480 level rise that increase depth can alter the relative influence of marine and river effects, for a given 481 storm surge and river flow. Similarly, a decrease in mean river discharge, as has occurred in many 482 places due to flow regulation, may also cause a landward migration in the crossover point (Fig. 483 11).

484 Other factors that influence long-wave amplitudes also influence the crossover point, including the 485 time scale of the surge (Fig. 7), convergence $L_{e}$ (Fig. 8), the boundary amplitude, and the relative 486 phasing of tides and surge (see Familkhalili et al., 2020). The influence of many of these factors 487 is explained by considering the non-dimensional friction number $\left(\psi=\frac{c_{d} \xi \omega^{2} L_{e}^{3}}{g h^{3}}\right)$ (see Sect. 2.1). This 488 number suggests that increases in channel depth $(h)$, wave time scale $\left(T=\frac{1}{\omega}\right)$, and decreased length 489 scale $\left(L_{e}\right)$ have similar effects on wave amplitudes. For example, increasing the depth from $5 \mathrm{~m}$ 
$490 \quad(\psi=69)$ to $15 \mathrm{~m}(\psi=2.6)$ causes $A_{*}$ (i.e., normalized amplitude by ocean boundary amplitude) 491 to increase from $\sim 0.06$ to 0.26 (Fig. 8a). Similarly, changing the surge time scale from 12 to $60 \mathrm{~h}$ 492 ( $\psi=69$ to 2.8 ) changes $A_{*}$ from $\sim 0.06$ to 0.22 for a $5 \mathrm{~m}$ channel depth.

493 Others such as Bilskie and Hagen (2018) have defined flood zone transitions between marine and 494 fluvial dominance; close to coast, tide and surge based flooding dominates, while river floods 495 dominate far upstream. In between, there is a transition zone with compound flooding in which 496 both coastal and fluvial processes are important. Here, our model also suggests that the transition 497 zone may be sensitive to changes in estuary geometry, such as depth, in addition to being 498 dependent on the relative strength of river flow, tide, and surge amplitudes.

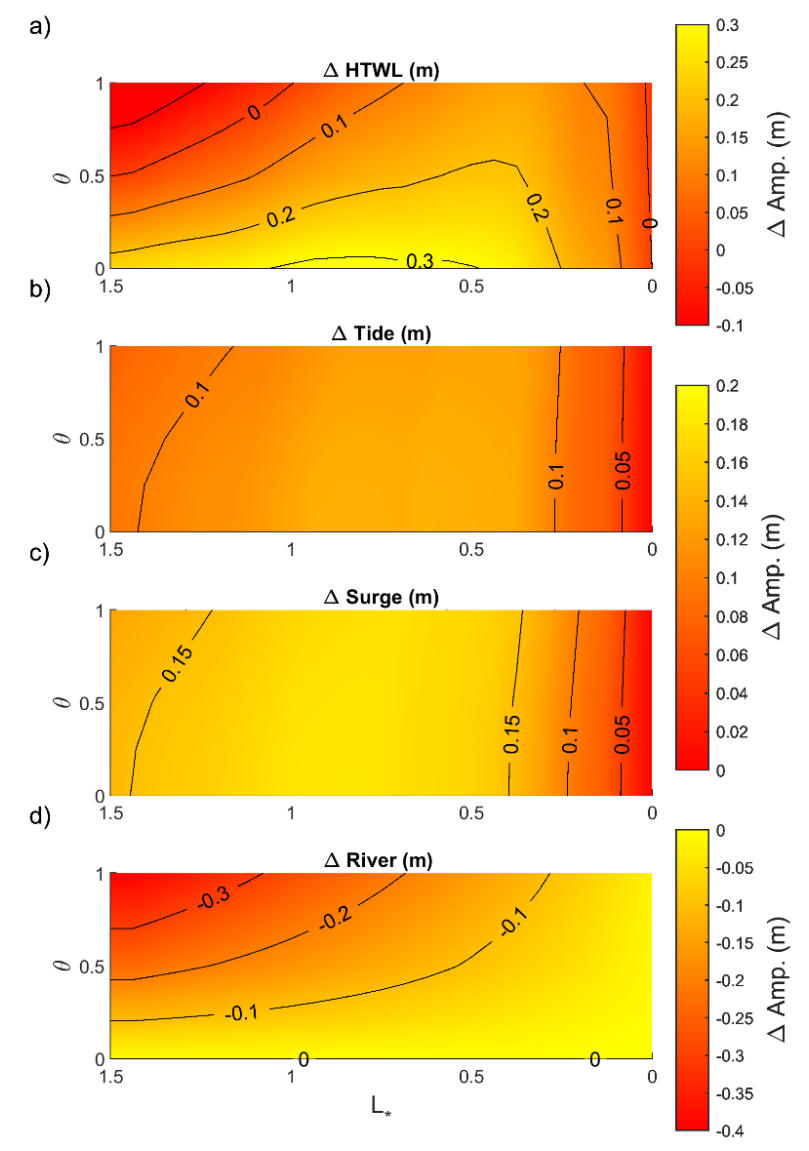


504

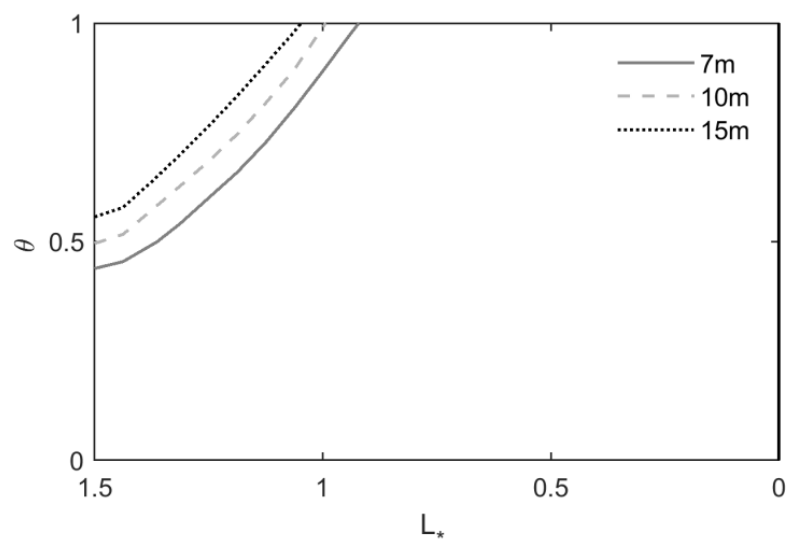

Figure 11: Crossover point location for 7-15m channel depth compared to $5 \mathrm{~m}$ case, $\left(S u_{\text {Pri }}=24 \mathrm{~h}\right.$ and $\left.L_{e}=80 \mathrm{~km}\right) . x$ axis represents dimensionless coordinate system of $L_{*}=x / L_{e}$ and $y$-axis shows non-dimensional river flow $(\theta=$ $\left.\frac{\left|u_{r}\right|}{\left|u_{D_{2}}\right|}\right)$.

\section{3-5- Comparison with numerical model}

Our model provides insights into how and why changes to depth, surge time scale, and convergence length-scale affect the damping/amplification of surge in real estuaries. For validation and further insights, we compare the analytical results to the idealized numerical modeling of Familkhalili and Talke (2016). As shown in Familkhalili and Talke (2016), the Cape Fear River Estuary is an example of a strongly convergent estuary with an $e$-folding length scale of $\sim 20 \mathrm{~km}$ upstream of river kilometer $(\mathrm{Rkm}) 12$. Over the past 125 years, the shipping channel was increased from $7 \mathrm{~m}$ to $15 \mathrm{~m}$ depth, which resulted in a near doubling of tidal range and a large (modeled) increase in storm surge.

We next compare our analytical results at $\sim L_{*}=1.5$ with the results of Familkhalili and Talke (2016) at Wilmington, NC, using a time scale of $12 \mathrm{~h}$. For a shallow estuary of $7 \mathrm{~m}$ that is consistent with late $19^{\text {th }}$ century conditions in the Cape Fear, our results show that the storm surge wave is damped by $\sim 40 \%$ (from $0.5 \mathrm{~m}$ to $0.3 \mathrm{~m}$ ) between the coast and $L_{*}=1.5$ (Fig. 8b, Fig. 12). This damping is within the range of modeled results for a tropical storm surge at Wilmington $\left(L_{*} \sim 1.5\right.$, Fig. 12). In a modern configuration (mean depth $=15 \mathrm{~m}$ ), the analytical model (this paper) finds a $12 \%$ increase (i.e., $A_{*}=1.12$ ) in surge amplitude, while the numerical model of Familkhalili and Talke (2016) shows a range of $A_{*}=0.55-1.35$ at Wilmington (Fig. 12). Hence, both the sense of change and the order of magnitude of change is consistent between the numerical and analytical model, improving our confidence in results. We conclude that in a shallow estuary the effects of friction are dominant over the convergence and cause the wave amplitudes (tides and surge) to 
decrease, while deepening the estuary may cause amplification of long-waves upriver of an estuary. As shown in Fig. 8, the amplification in storm surge is particularly acute when the estuary is highly convergent; hence, estuaries such as the Cape Fear may be particular to depth-induced shifts in storm surge amplitudes.

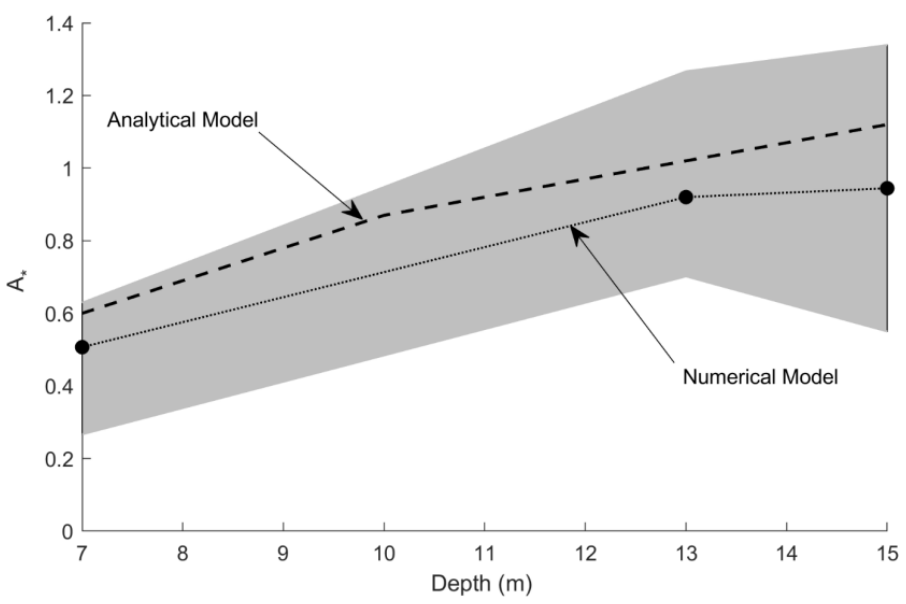

Figure 12: Numerical modeled storm surge at Wilmington, NC produced by tropical storm hurricane with mean around the mean is the range of results due to different relative phase of the storm surge and tide wave. The black dashed line (labeled 'Analytical model') represents damping of a $12 \mathrm{~h}$ surge with an amplitude of $0.5 \mathrm{~m}\left(A_{*}\right.$ is normalized amplitude and equals one at the ocean boundary). The analytical model results are replotted from Fig. $8 b$.

\section{4- Conclusion}

540 In this study, we have applied a new river-tide-surge analytical model to investigate the 541 interactions of tide, surge, and river flow along idealized estuaries. We show that the rate of 542 damping in a storm tide (surge + tide) is sensitive to fluctuations of river discharge (Fig. 7), 543 alterations in the surge time scale (Fig. 7), and channel geometry changes (depth and width 544 convergence) (Fig. 8). Model results show that the crossover point, which is the location at which 545 the river flow effects are larger than marine effects, moves upstream as channel depth increases or 546 as river flow decreases (Fig. 11). Thus, the spatial variability in compound flood risk contributors 547 (i.e., tide, surge, and river flow) change when an estuary is modified, or river discharge changes. 548 Generally, increasing the surge time scale has a similar effect as increasing the depth; however, 549 we note that our model is slightly more sensitive to depth, due to the cubic relationship in the 550 friction term, rather than the squared effect of time scale. The non-dimensional friction number $551(\psi)$ suggest that the effects of surge amplitude at boundary $(\xi)$ and drag coefficient $\left(C_{d}\right)$ have a lesser, but still important, influence on the spatial damping of surge as the depth. 
553 Globally, natural and local anthropogenic changes in estuaries (e.g., sea-level rise, channel 554 deepening for navigation and landfilling) produce alterations in tidal and surge amplitudes (see 555 review by Talke and Jay, 2020, and references therein). This study shows that river flow and its 556 interaction with tides and surge must also be considered when evaluating changes to water levels. 557 For example, increasing the river discharge relative to tide velocity reduces the amplification of 558 the surge wave. Moreover, channel deepening produces a reduction in the water level caused by 559 river discharge, leading to a domain in which channel deepening produces lower water levels 560 upstream but larger water levels in the estuary (Fig. 9-11; see also Helaire et al, 2019 and Ralston 561 et al., 2019). Our findings are consistent with other studies that find that reduced frictional effects 562 (e.g., caused by channel deepening) can cause increases to tides and surge (see e.g., Ralston et al., 563 2019; Talke et al., 2021). Hence, the spatial characteristics of compound flooding may shift over 564 time due to anthropogenically-induced changes to geometry.

\section{5- Author contribution}

566 Ramin Familkhalili: Methodology, Software, Validation, Formal analysis, Investigation, Data 567 Curation, Writing - Original Draft, Writing - Review \& Editing, Visualization

568 Stefan Talke: Conceptualization, Methodology, Formal Analysis, Resources, Writing - Review \& 569 Editing, Supervision, Project administration, Funding acquisition.

570 David Jay: Conceptualization, Methodology, Formal Analysis, Resources, Writing - Review \& 571 Editing, Supervision.

\section{6- Competing interests}

573 The authors declare that they have no conflict of interest.

\section{7- Data availability}

575 The data used are listed within the body of the manuscript and references.

\section{8- Acknowledgements}

577 Funding was provided by the US Army Corps of Engineers (award W1927N-14-2-0015) and the

578 National Science Foundation (awards 1455350 and 1854946). 


\section{9- References}

580

581

582

583

584

585

586

587

588

589

590

591

592

593

594

595

596

597

598

599

600

601

602

603

604

605

606

607

608

609

610

611

612

613

614

615

616

617

618

619

620

621

622

623

Bilskie, M. V. and Hagen, S. C.: Defining Flood Zone Transitions in Low-Gradient Coastal Regions, Geophys. Res. Lett., 45, 2761-2770, https://doi.org/10.1002/2018GL077524, 2018.

Buschman, F. A., Hoitink, A. J. F., Van Der Vegt, M., \& Hoekstra, P. (2009). Subtidal water level variation controlled by river flow and tides. Water Resources Research, 45, W10420. https://doi.org/10.1029/2009WR008167

Cai, H., H. H. G. Savenije, and M. Toffolon (2014), Linking the river to the estuary: influence of river discharge on tidal damping, Hydrol. Earth Syst. Sci., 18(1), 287-304, doi:10.5194/hess18-287-2014.

Dronkers, J. J. (1964), Tidal Computations in Rivers and Coastal Waters, North-Holland, New York, 296-304.

Familkhalili, R., and Talke, S. A. (2016), The effect of channel deepening on tides and storm surge: A case study of Wilmington, NC, Geophys. Res. Lett., 43, 9138-9147, doi:10.1002/2016GL069494.

Familkhalili, R., Talke, S. A., \& Jay, D. A. (2020). Tide-storm surge interactions in highly altered estuaries: How channel deepening increases surge vulnerability. Journal of Geophysical Research: Oceans, 125, e2019JC015286. https://doi.org/10.1029/2019JC015286

Friedrichs, C. T., and Aubrey, D. G. (1994), Tidal propagation in strongly convergent channels. Journal of Geophysical Research, 99(C2), 3321-3336. http://doi.org/10.1029/93JC03219

Giese, B. S., and D. A. Jay (1989), Modeling tidal energetics of the Columbia River estuary, Estuarine Coastal Shelf Sci., 29(6), 549-571, doi:10.1016/02727714(89)90010-3

Godin, G. (1985), Modification of rivertides by the discharge, J. Waterway, Port, Coastal, Ocean Eng., 1985, 111(2): 257-274

Godin, G. (1991), Compact approximations to the bottom friction term for the study of tides propagating in channels. Continental Shelf Research 11 (7), 579-589

Godin, G. (1999), The propagation of tides up rivers with special considerations on the upper Saint Lawrence River, Estuarine, Coastal and Shelf Science, 48, 307 - 324.

Godin, G., Martinez, A., (1994): Numerical experiments to investigate the effects of quadratic friction on the propagation of tides in a channel, Continental Shelf Research, Vol. 14, No. 7/8, pp. 723-748, 1994

Helaire, L. T., Talke, S. A., Jay, D. A., \& Mahedy, D. (2019). Historical changes in Lower Columbia River and estuary floods: A numerical study. Journal of Geophysical Research: Oceans, 124, 7926-7946. https://doi.org/10.1029/2019JC015055.

Helaire, L. T., Talke, S. A., Jay, D. A., \& Chang, H. (2020). Present and Future Flood Hazard in the Lower Columbia River Estuary: Changing Flood Hazards in the Portland-Vancouver Metropolitan Area. Journal of Geophysical Research: Oceans, https://doi.org/10.1029/2019JC015928

Horrevoets, A., H. Savenije, J. Schuurman, and S. Graas (2004), The influence of river discharge on tidal damping in alluvial estuaries, J. Hydrol., 294(4), 213-228.

Hoitink, A. J. F., and D. A. Jay (2016), Tidal river dynamics: Implications for deltas, Rev. Geophys., 54, 240-272, doi:10.1002/2015RG000507.

Jay, D. A. (1991). Green's law revisited: Tidal long-wave propagation in channels with strong topography. Journal of Geophysical Research, 96(C11), 20585. http://doi.org/10.1029/91JC01633 
Jay, D. A. and E. P. Flinchem (1997), Interaction of fluctuating river flow with a barotropic tide: A test of wavelet tidal analysis methods, J. Geophys. Res. 102:5705-5720.

Jay, D. A., K. Leffler and S. Degens (2011), Long-term evolution of Columbia River tides, ASCE Journal of Waterway, Port, Coastal, and Ocean Engineering, 137: 182-191; doi: 10.1061/(ASCE)WW.1943- 5460.0000082.

Jay, DA, A. Devlin, D. Idier, E. Prococki, and RE Flick, (2021), Tides and Geomorphology: Time Scales and Non-Stationary Processes, Coastal and Submarine Geomorphology, Treatise on Geomorphology, https://doi.org/10.1016/B978-0-12-818234-5.00166-8

Johnson, F., White, C.J., van Dijk, A. et al. Natural hazards in Australia: floods. Climatic Change 139, 21-35 (2016). https://doi.org/10.1007/s10584-016-1689-y.

Jongman B, Ward PJ, Aerts JCJH. Global exposure to river and coastal flooding: Long term trends and changes. Global Environmental Change 2012; 22(4): 823-35

Kästner, K., Hoitink, A. J. F., Torfs, P. J. J. F., Deleersnijder, E., \& Ningsih, N. S. (2019). Propagation of tides along a river with a sloping bed. Journal of Fluid Mechanics, 872, 3973. https://doi.org/10.1017/jfm.2019.331

Kukulka, T. \& D.A. Jay, (2003a). Impacts of Columbia River discharge on salmonid habitat: 1. A nonstationary fluvial tidal model. Journal of Geophysical Research v108 No. C9, doi:10.1029/2002JC001382

Kukulka, T. \& D.A. Jay, (2003b). Impacts of Columbia River discharge on salmonid habitat: 2. Changes in shallow-water habitat. Journal of Geophysical Research v108 No. C9, doi:10.1029/2002JC001829

Lanzoni, S., and G. Seminara, On tide propagation in convergent estuaries, J. Geophys. Res., 103, 30,793-30,812, 1998

Munchow, A. K., Masse, A. K. \& Garvine, R. W. 1992 Astronomical and nonlinear tidal currents in a coupled estuary shelf system. Continental Shelf Research 12, 471-498.

Nicholls, R.J., P.P. Wong, V.R. Burkett, J.O. Codignotto, J.E. Hay, R.F. McLean, S. Ragoonaden and C.D. Woodroffe, 2007: Coastal systems and low-lying areas. Climate Change 2007: Impacts, Adaptation and Vulnerability. Contribution of Working Group II to the Fourth Assessment Report of the Intergovernmental Panel on Climate Change, M.L. Parry, O.F. Canziani, J.P. Palutikof, P.J. van der Linden and C.E. Hanson, Eds., Cambridge University Press, Cambridge, UK, 315-356.

Nicholls RJ, Hoozemans FMJ, Marchand M. 1999. Increasing flood risk and wetland losses due to global sea-level rise: regional and global analyses. Glob. Environ. Change 9: S69-87

Olsen Associates Inc. (2012), Calibration of a Delft3D model for Bald Head Island and the Cape Fear River entrance phase 1, 6114(April).

Orton, P., Georgas, N., Blumberg, A., and Pullen, J. (2012), Detailed modeling of recent severe storm tides in estuaries of the New York City region, J. Geophys. Res., 117, C09030, doi:10.1029/2012JC008220.

Orton, P., Talke, S., Jay, D., Yin, L., Blumberg, A., Georgas, N., Zhao, H., Roberts, H., MacManus, K. (2015). Channel Shallowing as Mitigation of Coastal Flooding. Journal of Marine Science and Engineering, 3(3), 654-673. http://doi.org/10.3390/jmse3030654

Orton, P. M., T. M. Hall, S. Talke, A. F. Blumberg, N. Georgas, and S. Vinogradov, 2016: A validated tropical-extratropical flood hazard assessment for New York Harbor. J. Geophys. Res. Oceans, 121, 8904-8929, doi:https://doi.org/10.1002/2016JC011679 
Parker, B. B., 1991. The relative importance of the various nonlinear mechanisms in a wide range of tidal interactions. In: Progress in Tidal Hydrodynamics, Ed. by B. B. Parker, JohnWiley, pp. 237-268.

Prandle, D., and Rahman, M. (1980). Tidal response in estuaries. Journal of Physical Oceanography, 10(10), 1552-1573.

Ralston, D. K., Warner, J. C., Geyer, W. R., and Wall, G. R. (2013), Sediment transport due to extreme events: The Hudson River estuary after tropical storms Irene and Lee, Geophys. Res. Lett., 40, 5451- 5455, doi:10.1002/2013GL057906.

Ralston, D. K., Talke, S., Geyer, W. R., Al-Zubaidi, H. A. M., \& Sommerfield, C. K. (2019). Bigger tides, less flooding: Effects of dredging on barotropic dynamics in a highly modified estuary. Journal of Geophysical Research: Oceans,124, 196-211. https://doi.org/10.1029/2018JC014313

Savenije, H. H. G. (1998), Analytical expression for tidal damping in alluvial estuaries, J Hydraul Eng-Asce, 124(6), 615-618.

Savenije, H. H. G., M. Toffolon, J. Haas, and E. J. M. Veling (2008), Analytical description of tidal dynamics in convergent estuaries, J. Geophys. Res.,113, C10025, doi:10.1029/2007JC004408.

Talke, S. A., P. Orton, and D. A. Jay (2014), Increasing storm tides in New York Harbor, 18442013, Geophys. Res. Lett., 41, 3149-3155, doi:10.1002/2014GL059574.

Talke, S. A., Familkhalili, R., \& Jay, D. A. (2021). The influence of channel deepening on tides, river discharge effects, and storm surge. Journal of Geophysical Research: Oceans, 126, e2020JC016328. https://doi.org/10.1029/2020JC016328

Talke, S.A and D.A. Jay (2020). Changing tides: The role of natural and anthropogenic factors. Annual Review of Marine Science, https://doi.org/10.1146/annurev-marine-010419-010727

Toffolon, M., and H. H. Savenije (2011), Revisiting linearized one-dimensional tidal propagation, J. Geophys. Res.,116, C07007,doi:10.1029/2010JC006616.

van Oldenborgh, G. J., van der Wiel, K., Sebastian, A., Singh, R., Arrighi, J., Otto, F., et al. (2017). Attribution of extreme rainfall from Hurricane Harvey, August 2017. Environmental Research Letters, 12, 124009

Wahl, T., S. Jain, J. Bender, S. D. Meyers, and M. E. Luther (2015), Increasing risk of compound flooding from storm surge and rainfall for major US cities, Nat. Clim. Change,5(12), 10931097, doi:10.1038/NCLIMATE2736.

Wang, S.-Y. S., Zhao, L., Yoon, J.-H., Klotzbach, P., \& Gillies, R. R. (2018). Attribution of climate effects on Hurricane Harvey's extreme rainfall in Texas. Environmental Research Letters, 13. https://doi.org/10.1088/1748-9326/aabb85.

Winterwerp JC, Wang ZB, van Braeckel A, van Holland G, Kösters F. 2013. Man-induced regime shifts in small estuaries - II: a comparison of rivers. Ocean Dyn. 63:1293-306

Wong, P. P., I. J. Losada, J.-P. Gattuso, J. Hinkel, A. Khattabi, K. L. McInnes, Y. Saito, and A. Sallenger (2014), Coastal systems and low-lying areas, in Climate Change 2014: Impacts, Adaptation, and Vulnerability, Part A: Global and Sectoral Aspects, Contribution of Working Group II to the Fifth Assessment Report of the Intergovernmental Panel on Climate Change, edited by C. B. Field et al., pp. 361-409, Cambridge Univ. Press, Cambridge, U. K.

Zheng, F.; Westra, S.; Leonard, M.; Sisson, S.A. Modeling dependence between extreme rainfall and storm surge to estimate coastal flooding risk. Water Resour. Res. 2014, 50, 2050-2071.

Zscheischler, J., Westra, S., van den Hurk, B.J.J.M. et al. Future climate risk from compound events. Nature Clim Change 8, 469-477 (2018). https://doi.org/10.1038/s41558-018-0156-3 